\title{
Autoregulation of Phosphorylation of the Nicotinic Acetylcholine Receptor
}

\author{
Kathryn Miles, ${ }^{1}$ Sylvie S. M. Audigier, ${ }^{2}$ Paul Greengard, ${ }^{2}$ and Richard L. Huganir ${ }^{3}$ \\ 'Department of Anatomy and Cell Biology, The State University of New York Health Science Center at Brooklyn, \\ Brooklyn, New York 11203, ${ }^{2}$ The Laboratory of Molecular and Cellular Neuroscience, The Rockefeller University, New \\ York, New York 10021, and ${ }^{3}$ Howard Hughes Medical Institute, Department of Neuroscience, Johns Hopkins University, \\ Baltimore, Maryland 21205
}

\begin{abstract}
We have investigated the regulation of phosphorylation of the nicotinic ACh receptor (nAChR) in rat myotubes by the agonist carbamylcholine. Treatment of primary rat myotube cultures with carbamylcholine resulted in a $100 \%$ increase in phosphorylation of the nAChR $\gamma-(52 \mathrm{kDa})$ subunit and a $30 \%$ increase in phosphorylation of the nAChR $\delta-(62 \mathrm{kDa})$ and $\delta^{\prime}-(66 \mathrm{kDa})$ subunits. These responses to carbamylcholine were dose dependent, with a half-maximal response occurring at $10 \mu \mathrm{M}$ and a maximum response achieved within $2 \mathrm{~min}$.
\end{abstract}

Pretreatment of myotubes with d-tubocurare, but not with atropine, inhibited carbamylcholine-stimulated phosphorylation of the nAChR. Preincubation with open-channel blockers of the nAChR also inhibited phosphorylation of the nAChR induced by carbamylcholine.

Depletion of extracellular calcium from myotube cultures prevented carbamylcholine-stimulated increases in nAChR phosphorylation whereas application of a calcium ionophore mimicked the effect of carbamylcholine on nAChR phosphorylation. Pretreatment of myotubes with TTX did not inhibit carbamylcholine-stimulated $\mathrm{nAChR}$ phosphorylation and potassium depolarization of myotubes had no effect on nAChR phosphorylation.

Carbamylcholine increased nAChR phosphorylation to the same extent and with the same time course and subunit specificity as that induced by phorbol esters. However, chronic treatment of myotubes with phorbol esters that eliminated any subsequent phorbol ester-stimulated nAChR phosphorylation did not diminish the increase in nAChR phosphorylation induced by carbamylcholine. The calmodulin antagonist W7 was similarly unable to inhibit carbamylcholine-stimulated nAChR phosphorylation.

These results suggest that the nAChR is a substrate for an uncharacterized protein kinase in situ, and that activity of this protein kinase is stimulated by calcium ions that permeate through the activated $\mathrm{nAChR}$ ion channel. The data reveal a novel signal transduction pathway whereby the nAChR may autoregulate its own functional activity.

\footnotetext{
Received July 6, 1993; revised Oct. 20, 1993; accepted Nov. 17, 1993.

This work was supported by U.S. Public Health Service Grants NS29356 (K.M.) and MH40899 (P.G.) and the Muscular Dystrophy Association (R.L.H.).

Correspondence should be addressed to Kathryn Miles, State University of New York, Health Science Center at Brooklyn, Department of Anatomy and Cell Biology, Box 5, 450 Clarkson Avenue, Brooklyn, NY 11203.

Copyright (C) 1994 Society for Neuroscience 0270-6474/94/143271-09\$05.00/0
}

[Key words: nicotinic ACh receptor, protein phosphorylation, protein kinase, ion channel, carbamylcholine, calcium]

Protein phosphorylation is an important posttranslational modification that modulates nicotinic $\mathrm{ACh}$ receptor ( $\mathrm{AChR}$ ) functional activity (Huganir et al., 1986; Hopfield et al., 1988), assembly (Ross et al., 1987; Green et al., 1991), and postsynaptic distribution (Ross et al., 1988; Qu et al., 1990; Wallace et al., 1991). The nAChR present at the neuromuscular junction and in fish electric organs is a neurotransmitter-activated ion channel composed of five homologous protein subunits $\left(\alpha_{2} \beta \gamma \delta\right)$ (Changeux et al., 1984). In mammals, a developmental transition occurs in which the $\gamma$-subunit is replaced by the $\epsilon$-subunit with consequent changes in ion channel properties (Mishina et al., 1986). The phosphorylation sites on the nAChR subunits have been largely conserved and are proposed or have been demonstrated to be contained within a span of 20 amino acids in the major intracellular loop of each subunit (Yee and Huganir, 1987; Miles and Huganir, 1988; Wagner et al., 1991).

Several protein kinases phosphorylate the $\mathrm{nAChR}$ in vitro. cAMP-dependent protein kinase phosphorylates the $\gamma$ - and $\delta$-subunits of the Torpedo electric organ nAChR (Huganir and Greengard, 1983), protein kinase C (PKC) phosphorylates the $\delta$-subunit (Safran et al., 1987; Miles and Huganir, 1988) while a protein tyrosine kinase, endogenous to the Torpedo electric organ postsynaptic membrane, phosphorylates the $\beta-, \gamma-$, and $\delta$-subunits of the nAChR (Huganir et al., 1984). In addition, the $\mathrm{nAChR}$ isolated from $\mathrm{BC} 3 \mathrm{Hl}$ cells is phosphorylated in vitro on the $\delta$-subunit by phosphorylase kinase (Smith et al., 1989).

Phosphorylation of the $\mathrm{nAChR}$ occurs in muscle cells. The nAChR from rat (Miles et al., 1987) and chick (Ross et al., 1987) primary muscle cells and mouse BC3H1 cells (Smith et al., 1987) is phosphorylated in situ under basal conditions. Regulation of muscle nAChR phosphorylation by cAMP-dependent protein kinase has been demonstrated by the addition of forskolin to muscle cells in culture (Miles et al., 1987; Smith et al., 1987). Calcitonin gene-related peptide, a neuropeptide present in presynaptic motor neurons, is an endogenous first messenger that appears to regulate $\mathrm{cAMP}$-dependent protein kinase-mediated nAChR phosphorylation (Miles et al., 1989). Activation of $\beta$-adrenergic receptors also regulates $n A C h R$ phosphorylation by cAMP-dependent protein kinase (Smith et al., 1987, 1989).

nAChRs present on $\mathrm{BC} 3 \mathrm{H} 1$ cells and rat skeletal myotubes in culture are phosphorylated on tyrosine (Smith et al., 1987; Miles and Huganir, 1988). Recently, nAChR protein tyrosine 

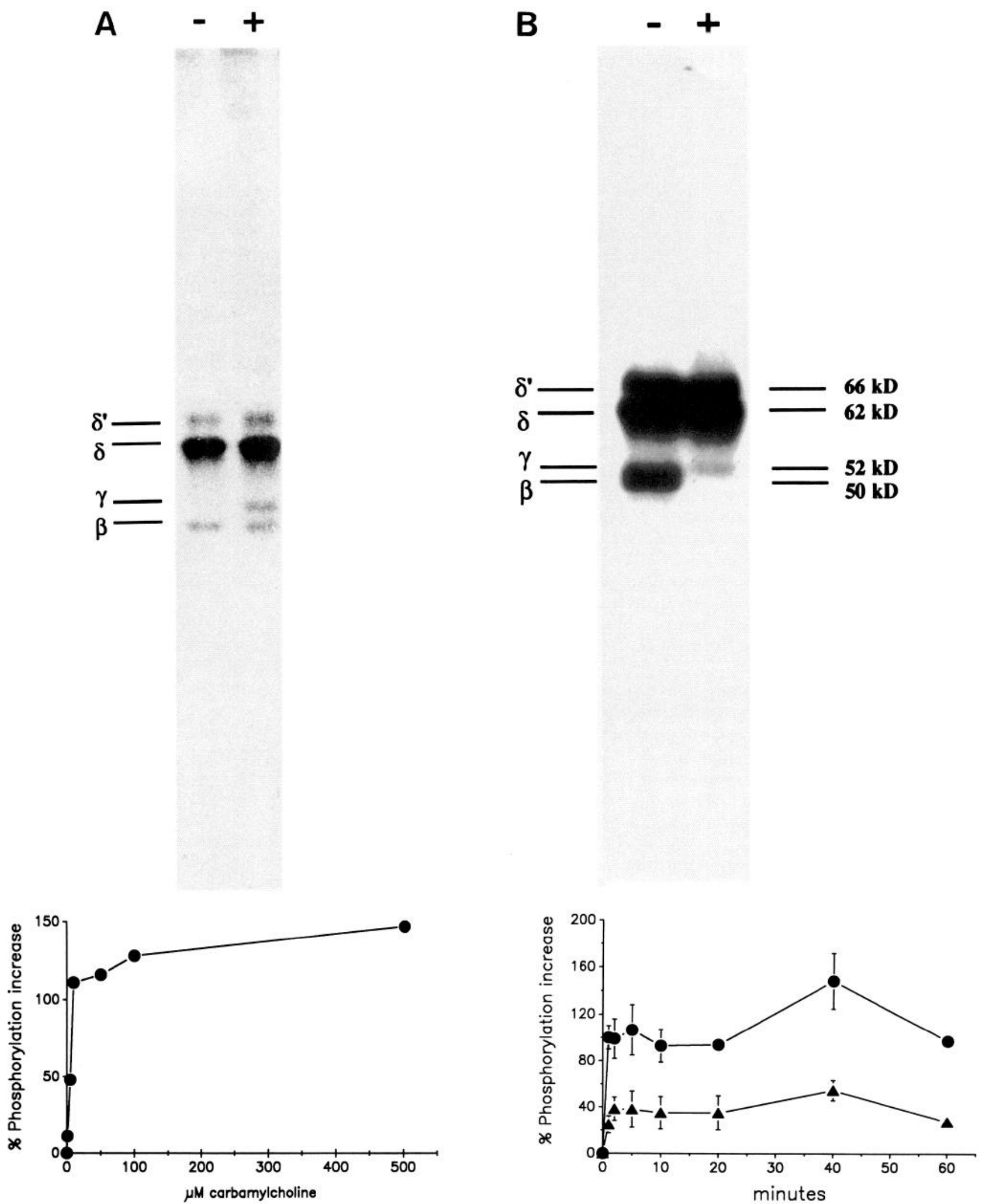

Figure 1. A, Effect of carbamylcholine on ACh receptor phosphorylation in myotube cultures. Rat muscle cell primary cultures were incubated with $1 \mathrm{mCi} / \mathrm{ml}{ }^{32} \mathrm{P}$-orthophosphate added to phosphate-free medium for $5 \mathrm{hr}$. Carbamylcholine (1 mm) was then added to cultures for $1 \mathrm{hr}$ (+lane). Myotube cultures were then solubilized and ACh receptors were isolated by ACh affinity chromatography followed by immunoaffinity chromatography. The receptor subunits were eluted with SDS-sample buffer and eluates from individual columns were analyzed by SDS-PAGE and autoradiography. $B$, Recognition of SDS-solubilized nAChR subunits by monoclonal antibody 88 -B. Rat muscle cell primary cultures were incubated with $5 \mathrm{mCi} / \mathrm{ml}^{32} \mathrm{P}$-orthophosphate and carbamylcholine as described for $A$. Myotube cultures were then solubilized and ACh receptors were isolated by ACh affinity chromatography followed by immunoaffinity chromatography ( - lane). After elution from an ACh column with 25 $\mathrm{mm}$ carbamylcholine, ACh receptors were incubated with $1 \%$ SDS for $5 \mathrm{~min}$. Triton X-100 was then added to a final concentration of $5 \%$ and the 
phosphorylation in the rat neuromuscular junction was demonstrated to be dependent upon innervation (Qu et al., 1990). The $\mathrm{nAChR}$ clustering factor agrin, isolated from Torpedo electric organs, regulates $\mathrm{nAChR}$ tyrosine phosphorylation in chick myotube cultures (Wallace et al., 1991).

Regulation of phosphorylation of muscle nAChRs by the second messenger calcium has previously been demonstrated by the addition of calcium ionophores to BC3H1 cells (Smith et al., 1988). Moreover, regulation of nAChR phosphorylation by the calcium-sensitive PKC has been observed in chick myotubes (Ross et al., 1988), but not in BC3H1 cells (Smith et al., 1989), following application of phorbol esters to myotubes. An agonist for the $\mathrm{nAChR}$, carbamylcholine, mimics the effect of phorbol esters on nAChR phosphorylation in chick myotubes (Ross et al., 1988). However, the biochemical mechanism that might link agonist activation of nAChRs with an increase in PKC mediated phosphorylation was not investigated.

In the present study we demonstrate that treatment of myotubes with the agonist carbamylcholine increases phosphorylation of the nAChR $\gamma$-and $\delta$-subunits through the activation of nAChRs. We demonstrate that calcium entering the cell through the activated $\mathrm{nAChR}$ is the likely second messenger that directly stimulates a protein kinase. This calcium-sensitive protein kinase activity persists in myotubes despite the specific downregulation of PKC and in the presence of calmodulin inhibitors. These results suggest a model whereby the nAChR stimulates phosphorylation of itself by conducting calcium ions that activate a yet-to-be characterized protein kinase.

\section{Materials and Methods}

Cell culture and metabolic labeling. Cultures of primary muscle cells were established from hindlimb muscles of 20-21 d rat embryos. Myoblasts were enzymatically dissociated with $0.5 \%$ trypsin and cultured in Dulbecco's modified Eagle's medium (GIBCO, Grand Island, NY) supplemented with $20 \%(\mathrm{v} / \mathrm{v})$ fetal calf serum and $33 \mathrm{~mm}$ glucose. After 2 $\mathrm{d}$, this medium was replaced with medium containing $10 \%(\mathrm{v} / \mathrm{v})$ horse serum and $2 \%(\mathrm{v} / \mathrm{v})$ chicken embryo extract to promote muscle cell differentiation and experiments were performed on 7-10-d-old myotube cultures. For metabolic labeling with radioactive phosphate, the culture medium was replaced with phosphate-free Eagle's minimal essential medium (Flow Laboratories, McLean, VA), ${ }^{32} \mathrm{P}$-orthophosphate $(1 \mathrm{mCi} /$ $\mathrm{ml}$ ) (New England Nuclear, Beverly, MA) was added, and the cells were incubated for $5 \mathrm{hr}$. This procedure has been shown to be sufficient to achieve isotopic equilibrium of ${ }^{32} \mathrm{P}$-orthophosphate with ATP and the nAChR (Miles et al., 1987; Smith et al., 1987). For metabolic labeling with ${ }^{32} \mathrm{P}$-phosphate in the absence of calcium, cultures were rinsed with $1 \mathrm{ml}$ of Tris-buffered saline and then incubated with $1 \mathrm{mCi} / \mathrm{ml}{ }^{32} \mathrm{P}-$ orthophosphate in calcium- and phosphate-free Eagle's minimal essential medium for $5 \mathrm{hr}$.

Incubation with effectors. After metabolic labeling with radioactive phosphate, myotubes were incubated with the following effectors for various durations and concentrations. Phorbol 12-myristate 13-acetate (PMA) and 4- $\alpha$-phorbol 12-myristate 13-acetate (4- $\alpha$-PMA) (LC Services Corp., Woburn, MA) were dissolved in dimethyl sulfoxide. Forskolin, Ro 20-1724, and ionomycin were dissolved in 95\% ethanol; nitrendipine and verapamil were dissolved in acetone and then diluted into $95 \%$ ethanol. All other compounds used in this study were dissolved in water.
For long-term phorbol ester treatment, myotube cultures were preincubated with active or inactive phorbol esters, the medium was removed and replaced by radioactively labeled medium for metabolic labeling.

Nicotinic ACh receptor isolation. Cultured myotubes were rinsed with isotonic PBS and nAChRs were solubilized from each $35 \mathrm{~mm}$ culture dish using a lysis solution containing $1 \%$ Triton X-100 in the presence of protease and phosphatase inhibitors as previously described (Miles et al., 1987). Insoluble material from each culture extract was removed by centrifugation for $1 \mathrm{~min}$ at $10,000 \times \mathrm{g}$, and the supernatants containing $n A C h R$ were passed through individual $A C h$ affinity columns (Reynolds and Karlin, 1978). The columns were rinsed with lysis solution, and the $\mathrm{AChR}$ complex was eluted from the affinity resin with lysis solution containing $25 \mathrm{~mm}$ carbamylcholine. The eluate from each ACh affinity column was then immediately passed through individual immunoaffinity columns consisting of monoclonal antibody 88-B (Froehner et al., 1983) linked to protein A-Sepharose (Pharmacia, Piscataway, NJ) by a rabbit anti-mouse IgG (Dako, Santa Barbara, CA). The columns were washed with lysis solution, and the $\mathrm{nAChR}$ subunits were eluted from the immunoaffinity columns with sample buffer containing $125 \mathrm{~mm}$ Tris (pH. 6.8), 2\%(w/v) SDS, $10 \%(\mathrm{v} / \mathrm{v})$ glycerol, and $5 \%(\mathrm{v} / \mathrm{v}) \beta$-mercaptoethanol. The yields of $\mathrm{nAChR}$ from parallel cultures were virtually identical. Eluates from immunoaffinity columns were subjected to electrophoresis on $9 \%$ SDS-polyacrylamide gels (Laemmli, 1970). Gels were then dried and autoradiographed.

\section{Results}

Effect of carbamylcholine on $n A C h R$ phosphorylation. Rat myotube cultures were treated with carbamylcholine to examine the regulation of $\mathrm{nAChR}$ phosphorylation by this agonist. Carbamylcholine increased phosphorylation of the nAChR $\delta$ - (62 $\mathrm{kDa})$ and $\delta^{\prime}-(66 \mathrm{kDa})$ subunits as well as of a $52 \mathrm{kDa} \mathrm{nAChR}$ subunit (Fig. 1 $A$ ). The $\delta^{\prime}$-subunit has a phosphopeptide map identical to that of the $\delta$-subunit and probably differs from it only by posttranslational modification. The $52 \mathrm{kDa}$ subunit is likely to be the rat nAChR $\gamma$-subunit for the following reasons. Phosphopeptide maps of the rat $\mathrm{nAChR} \beta-(50 \mathrm{kDa})$ and 52 $\mathrm{kDa}$ subunits are distinct from each other. In addition, metabolic ${ }^{35} \mathrm{~S}$-methionine labeling reveals that the $52 \mathrm{kDa}$ subunit is present at the same level as the $\beta$-subunit under basal as well as stimulated conditions. Monoclonal antibody $88-\mathrm{B}$, which is specific for the $\gamma$ - and $\delta$-subunits of the Torpedo nAChR, recognizes the rat $\mathrm{nAChR} \delta$-, $\delta^{\prime}$-, and $52 \mathrm{kDa}$ subunits, but not the $\alpha-(42 \mathrm{kDa})$ or $\beta$-subunits (Fig. $1 B)$. Moreover, the molecular weight of the $52 \mathrm{kDa}$ subunit is consistent with it being the rat nAChR $\gamma$-subunit.

Carbamylcholine stimulated nAChR phosphorylation in a dose-dependent manner with a half-maximal effect occurring in the range of $10 \mu \mathrm{M}$ (Fig. $1 C$ ). Examination of the time course of the effect of carbamylcholine on $\mathrm{nAChR}$ phosphorylation revealed that maximal levels of phosphorylation both for $\mathrm{NAChR}$ $\gamma$ - and $\delta$-subunits were achieved within $2 \mathrm{~min}$ after the application of carbamylcholine to myotube cultures (Fig. 1D). Quantitation of the phosphorylation increase indicated that phosphorylation of the $\delta$ - and $\delta^{\prime}$-subunits increased $40 \%$ whereas phosphorylation of the $\gamma$-subunit more than doubled. Previous determinations of the specific activity of intracellular ATP and the amount of $\mathrm{nAChR}$ isolated under identical conditions sug-

solubilized $\mathrm{n} \Lambda \mathrm{ChR}$ subunits were isolated by immunoaffinity chromatography ( I lane). The receptor subunits were eluted with SDS-sample buffer and eluates from individual columns were analyzed as described for $A$. $C$, Dose dependence of the effect of carbamylcholine on ACh receptor phosphorylation in myotube cultures. Rat muscle cell primary cultures were metabolically labeled with radioactive phosphate as described for $A$. Carbamylcholine was added to the cultures for $1 \mathrm{hr}$ at the indicated concentrations. ACh receptors were isolated and analyzed as described for $A$. The ACh receptor $\gamma$-subunit was excised from the gel and the ${ }^{32} \mathrm{P}$-phosphate content was quantitated by liquid scintillation counting. $D$, Time course of the effect of carbamylcholine on ACh receptor phosphorylation in myotube cultures. Rat muscle cell primary cultures were metabolically labeled with radioactive phosphate as described for $A$. Carbamylcholine $(500 \mu \mathrm{M})$ was added to the cultures for the indicated durations. ACh receptor $\gamma-(\bullet)$ and $\delta-(\Lambda)$ subunits were isolated and analyzed as described for $B$. Error bars indicate SEM of three samples. 


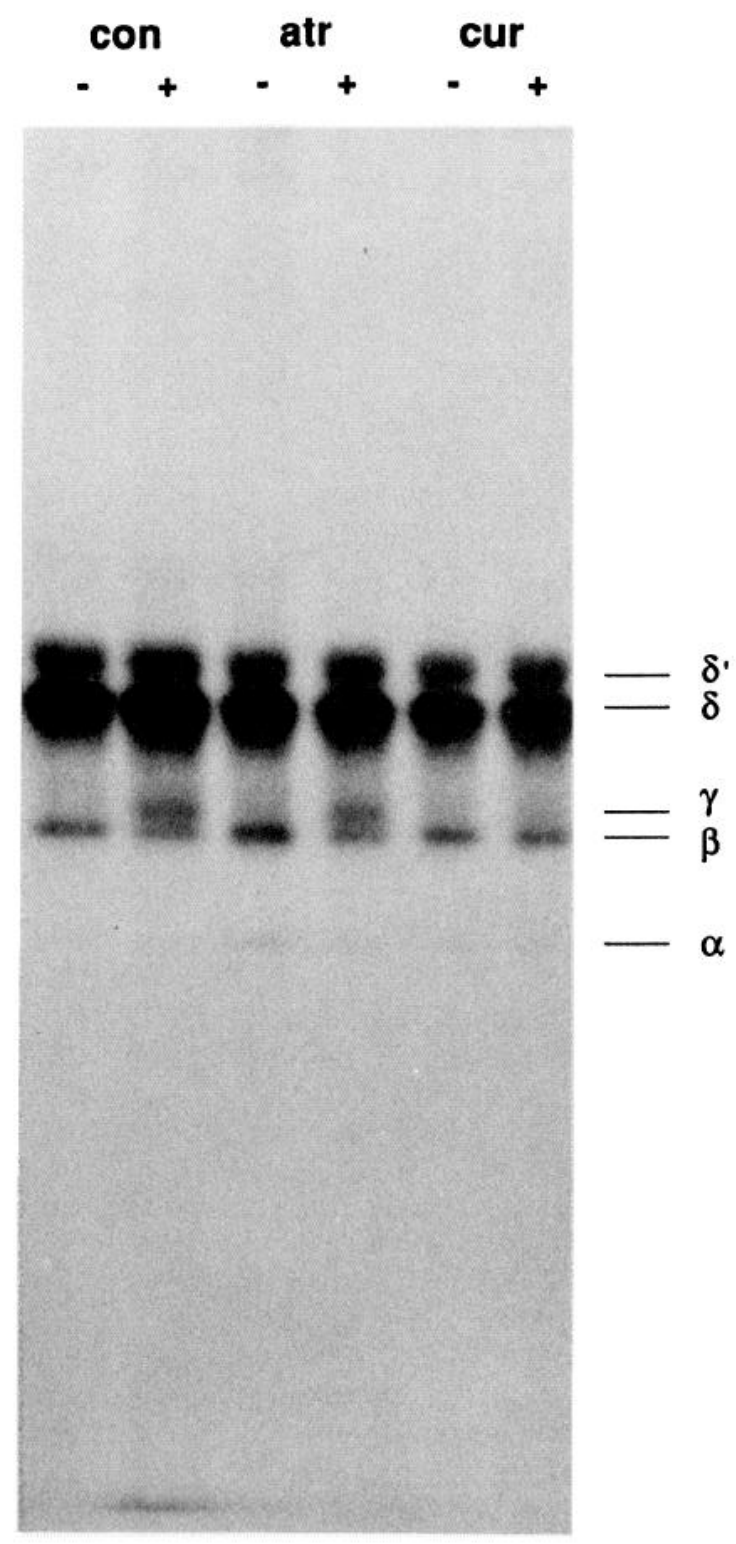

Figure 2. Effect of atropine or $d$-tubocurare on carbamylcholine-stimulated $\mathrm{ACh}$ receptor phosphorylation in myotube cultures. Rat muscle cell primary cultures were metabolically labeled as described for Figure $1 \mathrm{~A}$. Atropine $(a t r)(10 \mu \mathrm{M})$ or $d$-tubocurare $(c u r)(200 \mu \mathrm{M})$ was added 10 min prior to the addition of water $(-)$ or carbamylcholine $(+)(100$ $\mu \mathrm{M})$ for $30 \mathrm{~min}$. Myotube cultures were then solubilized and $\mathrm{ACh}$ receptors were isolated and analyzed as described for Figure $1 \mathrm{~A}$.

gests that the stoichiometry of phosphorylation of the $\delta$-subunit increased from $1.7 \mathrm{~mol}$ of phosphate to $2.6 \mathrm{~mol}$ of phosphate per mole of nAChR. Phosphorylation of the $\gamma$-subunit increased from $0.07 \mathrm{~mol}$ of phosphate to $0.2 \mathrm{~mol}$ of phosphate per mole of $\mathrm{nAChR}$. In subsequent experiments reported here, quantitation of phosphorylation increases was done on the $\gamma$-subunit because of the relatively smaller and more variable percentage increase in $\delta$-subunit compared to $\gamma$-subunit phosphorylation.

Pharmacologic specificity of carbamylcholine-stimulated $n A C h R$ phosphorylation. The contributions of muscarinic and/ or nicotinic $\mathrm{ACh}$ receptors in stimulating $\mathrm{nAChR}$ phosphorylation were assessed by preincubating myotubes with atropine or $d$-tubocurare before the application of carbamylcholine (Fig.
2). Carbamylcholine-stimulated increases in $\mathrm{AAChR}$ phosphorylation were not inhibited by preincubation of myotube cultures with atropine. This lack of inhibition was observed with concentrations ranging from $1 \mu \mathrm{M}$ to $1 \mathrm{~mm}$ carbamylcholine in the presence of atropine. The apparent increase in $\beta$-subunit phosphorylation after atropine treatment was not reproducible. In contrast, $d$-tubocurare completely inhibited nAChR phosphorylation stimulated by carbamylcholine.

$n A C h R$ open-channel blockers inhibit carbamylcholine-stimulated phosphorylation. To investigate either the role of ion fluxes through the activated $\mathrm{nAChR}$ or the role of an agonistinduced conformational change in the $\mathrm{nAChR}$ as possible mechanisms for mediating carbamylcholine-stimulated nAChR phosphorylation, myotubes were preincubated with open channel blockers of the nAChR (Fig. $3 A, B$ ) before the application of carbamylcholine. QX314 and quinacrine were each able to abolish carbamylcholine-stimulated nAChR phosphorylation in a dose-dependent manner. Neither QX314 nor quinacrine had any effect on $\mathrm{nAChR}$ phosphorylation in the absence of carbamylcholine.

Effect of extracellular calcium on carbamylcholine-stimulated $n A C h R$ phosphorylation. The possible role of calcium entrance through the activated $\mathrm{nAChR}$ acting as a second messenger was examined by treating myotubes with carbamylcholine under conditions in which calcium had been depleted from the extracellular medium (Fig. 4). In myotube cultures preincubated with EGTA prior to the application of carbamylcholine, increased phosphorylation of the $\mathrm{nAChR}$ was abolished compared to control cultures. Carbamylcholine-induced nAChR phosphorylation increases were also inhibited in cultures metabolically labeled in calcium-free medium (Fig. 4). Unimpaired responses to forskolin treatment were still observed in these cultures (data not shown).

Effect of ionomycin on $n A C h R$ phosphorylation. Ionomycin, a calcium ionophore, was found to mimic the effect of carbamylcholine on nAChR phosphorylation (Fig. 5). Myotubes preincubated with EGTA prior to the application of ionomycin exhibited no increase in nAChR phosphorylation.

Effect of TTX on carbamylcholine-stimulated increase in $n A C h R$ phosphorylation. Myotube cultures were preincubated with TTX before the application of carbamylcholine (Fig. 6) to determine whether activation of sodium channels, the production of an action potential, and the release of calcium from intracellular stores were involved in mediating the carbamylcholine-stimulated increase in $\mathrm{nAChR}$ phosphorylation. TTX (0.5-5 $\mu \mathrm{M})$ had no effect on the carbamylcholine-stimulated increase in $\mathrm{nAchR}$ phosphorylation.

Effect of potassium depolarization on $n A C h R$ phosphorylation. Myotubes were treated with potassium chloride $(\mathrm{KCl})$ (Fig. 6) to determine whether membrane depolarization could mimic the effect of carbamylcholine on nAChR phosphorylation. Treatment with $30-50 \mathrm{~mm} \mathrm{KCl}$ for between $30 \mathrm{sec}$ and $30 \mathrm{~min}$ had no effect on nAChR phosphorylation.

Effect of calcium channel antagonists and agonists on $n A C h R$ phosphorylation. To investigate the role of L-type voltage-sensitive calcium channels in mediating carbamylcholine-induced nAChR phosphorylation, myotubes were preincubated with dihydropyridine receptor antagonists prior to the application of carbamylcholine. Verapamil and nitrendipine each partially inhibited carbamylcholine-stimulated $\mathrm{nAChR}$ phosphorylation (data not shown). However, incubation of myotubes with the calcium-channel agonist Bay K-8644 (Strübing et al., 1993), 

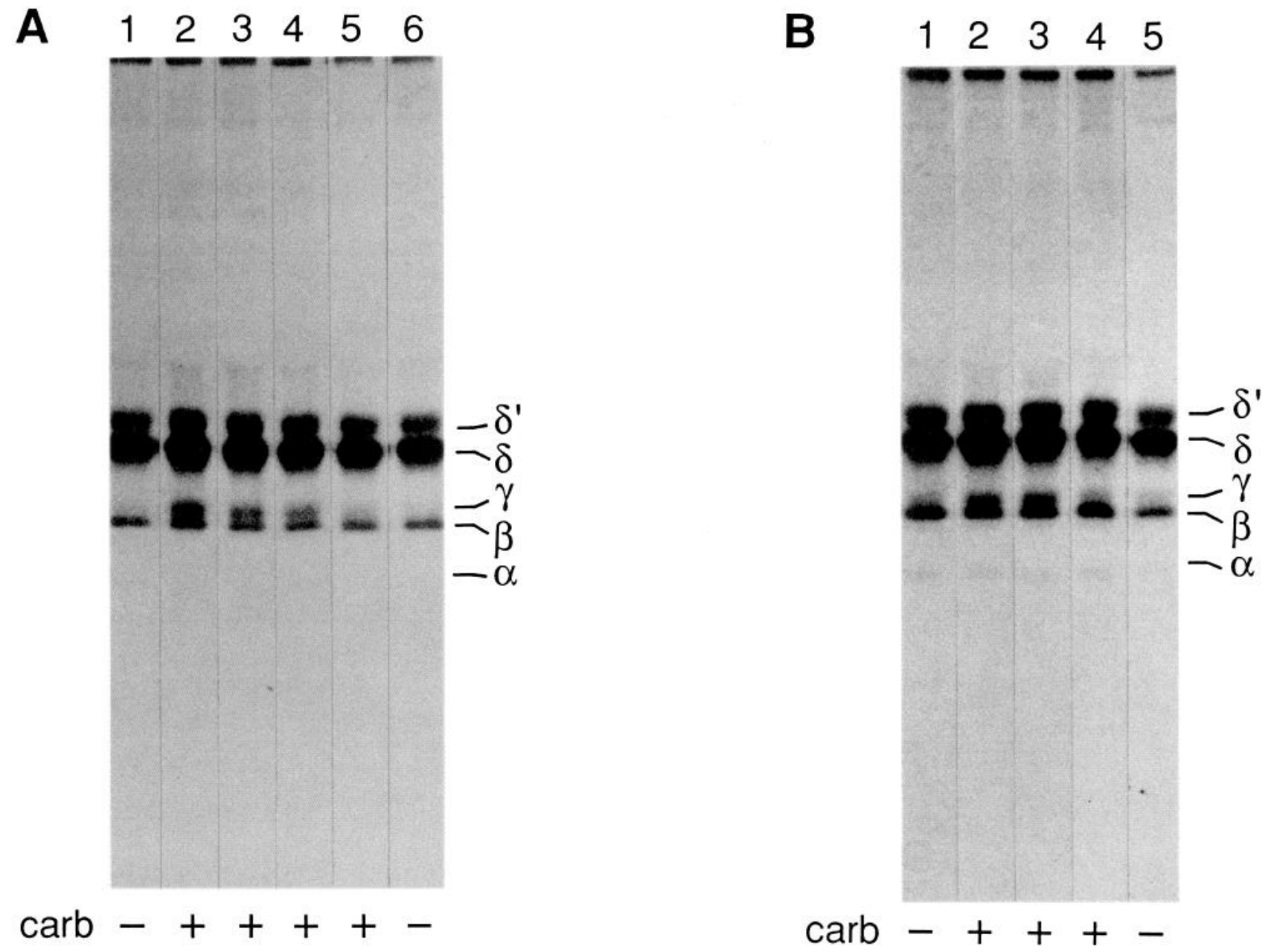

Figure 3. A, Dose dependence of the effect of QX314 on carbamylcholine-stimulated ACh receptor phosphorylation. Rat muscle cell primary cultures were metabolically labeled with radioactive phosphate as described for Figure $1 \mathrm{~A}$. QX314 was added to cultures $\left(10^{-5} \mathrm{M}\right)($ lane 3$)$, $\left(10^{-4}\right.$ м) (lane 4), $\left(10^{-3} \mathrm{M}\right)$ (lanes 5 and 6$)$ for $15 \mathrm{~min}$ prior to the addition of water $(-)$ or carbamylcholine $(500 \mu \mathrm{M})(+)$ for $10 \mathrm{~min}$. Myotube cultures were solubilized and $\mathrm{ACh}$ receptors were isolated and analyzed as described for Figure $1 A$. B. Dose dependence of the effect of quinacrine on carbamylcholine-stimulated ACh receptor phosphorylation. Rat muscle cell primary cultures were metabolically labeled with radioactive phosphate as described for Figure $1 \mathrm{~A}$. Quinacrine was added to cultures $\left(10^{-5} \mathrm{M}\right)$ (lane 3), $\left(10^{-4} \mathrm{M}\right)$ (lanes 4 and 5$)$ for 15 min prior to the addition of water $(-)$ or carbamylcholine $(500 \mu \mathrm{M})(+)$ for $10 \mathrm{~min}$. Myotubes cultures were solubilized and ACh receptors were isolated and analyzed as described for Figure $1 A$.

either alone or under depolarizing conditions ( $30 \mathrm{~mm} \mathrm{KCl),} \mathrm{had}$ no effect on nAChR phosphorylation (data not shown).

Effect of long-term phorbol ester treatment on $n A C h R$ phosphorylation. To examine the possible role of PKC in mediating carbamylcholine-stimulated phosphorylation of the nAChR, myotubes were chronically treated with an inactive phorbol ester derivative or phorbol esters to downregulate PKC activity specifically (Solanski et al., 1981). Myotube cultures were then metabolically labeled with ${ }^{32} \mathrm{P}$-phosphate and stimulated with carbamylcholine, phorbol ester, or forskolin plus the phosphodiesterase inhibitor Ro 20-1724. Downregulation of PKC activity was verified by monitoring phosphatidylserine/dioleinand calcium-dependent phosphorylation of a PKC substrate peptide in an in vitro assay that indicated that less than $10 \%$ of total PKC activity remained in myotubes after treatment with $200 \mathrm{~nm}$ phorbol ester for $1 \mathrm{hr}$ (data not shown).

Phorbol esters increased nAChR phosphorylation to the same extent and with the same time course (data not shown) and subunit specificity as that induced by carbamylcholine (Fig. 7A). Chronic phorbol ester treatment caused a $10-30 \%$ reduction in
nAChR labeling compared to control cultures consistent with the observation that phorbol ester treatment inhibits $\mathrm{nAChR}$ expression (Bursztajn et al., 1988). Moreover, chronic phorbol ester treatment followed by reapplication of phorbol esters resulted in no increase in nAChR phosphorylation. In contrast, the percentage increase in carbamylcholine-induced phosphorylation of the nAChR $\gamma$-subunit was unaffected by chronic phorbol ester treatment (Fig. 7A,B). The percentage increase in $\mathrm{nAChR}$ phosphorylation induced by forskolin, which increases phosphorylation of the nAChR $\alpha-, \gamma-$, and $\delta$-subunits, was also unaffected under the same conditions.

\section{Discussion}

The present studies, aimed at elucidating the biochemical mechanisms that underlie the regulation of $\mathrm{nAChR}$ phosphorylation by carbamylcholine in situ, are one step in obtaining an understanding of the role of the agonist in modulating as well as mediating signal transduction at nicotinic cholinergic synapses.

Carbamylcholine induced an increase in nAChR $\gamma$ - and $\delta$-subunit phosphorylation that was inhibited by pretreatment of 


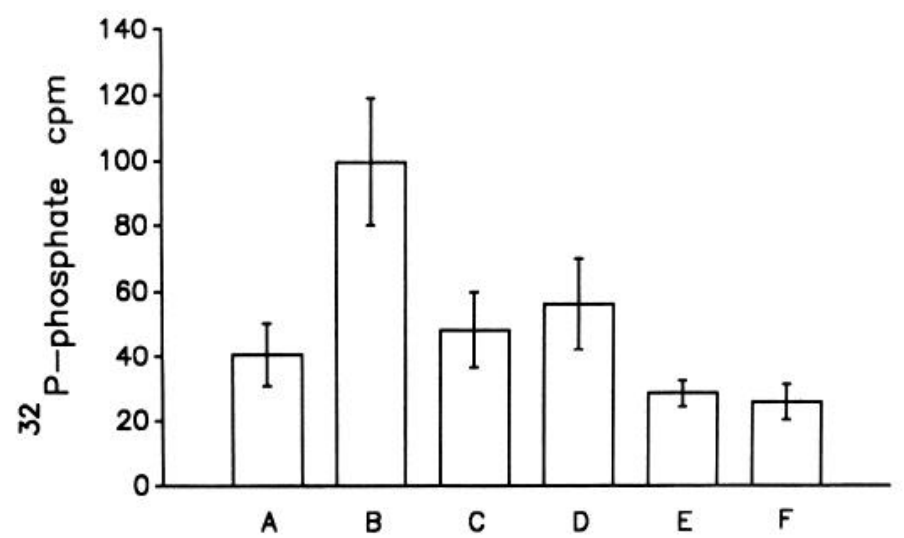

Figure 4. Effect of EGTA or calcium-free medium on carbamylcholine-stimulated $\mathrm{ACh}$ receptor phosphorylation in myotube cultures. Rat muscle cell primary cultures were metabolically labeled with $1 \mathrm{mCi} / \mathrm{ml}$ ${ }^{32} \mathrm{P}$-orthophosphate added to phosphate-free $(A, B, E, F)$ or calciumand phosphate-free $(C, D)$ medium for $5 \mathrm{hr}$. Cultures to be incubated with calcium- and phosphate-free medium were rinsed once with $1 \mathrm{ml}$ of Tris-buffered saline to diminish residual calcium levels. EGTA ( $E$, F) (2 mM), adjusted with $\mathrm{NaOH}$ to $\mathrm{pH} 7.0$, was added 5 min prior to the addition of water $(A, C, E)$ or carbamylcholine $(B, D, F)(500 \mu \mathrm{M})$ for $30 \mathrm{~min}$. Myotubes were solubilized and $\mathrm{ACh}$ receptors were isolated as described for Figure $1 \mathrm{~A}$. Assays were carried out in triplicate. The ACh receptor $\gamma$-subunit was excised from the gel and the ${ }^{32} \mathrm{P}$-phosphate content was quantitated by liquid scintillation counting. Error bars represent SEM.

myotubes with $d$-tubocurare but not with atropine. These results suggest that activation of muscarinic $\mathrm{ACh}$ receptors does not contribute to the regulation of $\mathrm{nAChR}$ phosphorylation in myotubes. Rather, it appears that carbamylcholine-stimulated phosphorylation of the $\mathrm{nAChR}$ is autoregulated. The evidence that open channel blockers of the $\mathrm{nAChR}$, agents that bind to the open state of the receptor ion channel and impede ion conductance, abolished carbamylcholine-stimulated nAChR phosphorylation further substantiates this hypothesis. Moreover, the results obtained with open channel blockers rule out the possibility that an agonist-activated conformational change in the nAChR facilitates its ability to serve as a substrate for ${ }^{\circ}$ constitutively active protein kinase. Taken together, these data suggest that ions flowing through the $\mathrm{nAChR}$ stimulate a protein kinase that in turn phosphorylates the nAChR.

Calcium has been shown to be a potent second messenger that regulates the activity of protein kinases and phosphatases. The $\mathrm{nAChR}$ is permeable, in its activated state, to divalent cations including calcium. It has been demonstrated that singlechannel calcium fluxes through the $\mathrm{nAChR}$ are significant and could potentially produce high intracellular calcium concentrations in the end-plate region (Decker and Dani, 1990; Giovanelli et al., 1991). To investigate the potential role of calcium in activating a protein kinase in response to application of carbamylcholine, calcium was removed from the extracellular medium either by EGTA treatment of myotube cultures or incubation in calcium-free medium. Both EGTA treatment and calcium-free medium abolished the ability of carbamylcholine to stimulate nAChR phosphorylation. In addition, ionomycin, a calcium ionophore, caused an increase in $\mathrm{nAChR}$ phosphorylation similar to that observed with carbamylcholine. These data suggest that calcium is an essential mediator of the signal initiated by carbamylcholine that resulted in $\mathrm{nAChR}$ phosphorylation.

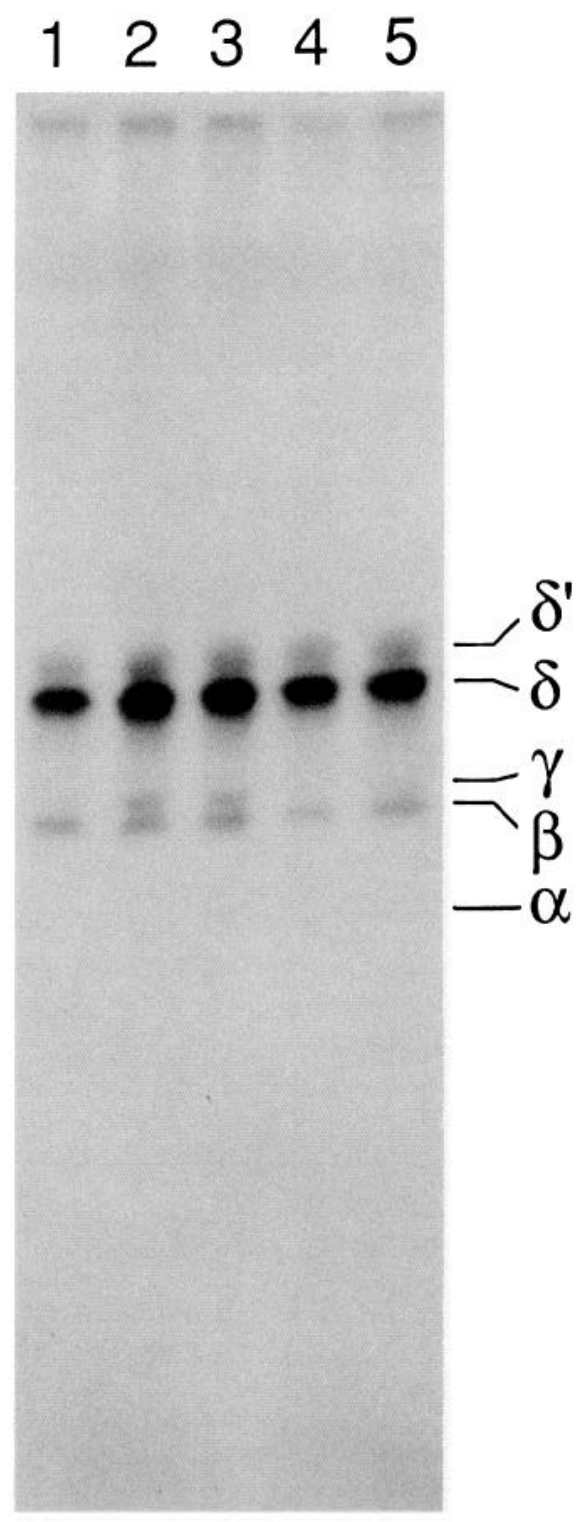

Figure 5. Effect of ionomycin on ACh receptor phosphorylation. Rat muscle cell primary cultures were metabolically labeled with radioactive phosphate as described for Figure 1A. EGTA (lanes 4 and 5) (2 mм) was added $5 \mathrm{~min}$ prior to the addition of water (lane 1 ), carbamylcholine (lane 2) $(500 \mu \mathrm{M})$, or ionomycin (lanes 3 and 4) $(10 \mu \mathrm{M})$ for $7 \mathrm{~min}$. Myotube cultures were then solubilized and $\mathrm{ACh}$ receptors were isolated and analyzed as described for Figure $1 \mathrm{~A}$.

The nAChR transduces its signal at the neuromuscular junction by conducting positive ions that depolarize the postsynaptic cell. Depolarization to a threshold voltage results in the generation of an action potential. Inactivation of voltage-sensitive sodium channels with TTX was unable to inhibit carbamylcholine-stimulated nAChR phosphorylation, indicating that an action potential was not required for carbamylcholine to stimulate nAChR phosphorylation. Myotube depolarization may also be achieved by raising extracellular potassium levels. Potassium chloride treatment has been shown to be effective in raising intracellular calcium concentrations in chick skeletal muscle (Schmid et al., 1984). Exposure of myotubes to high potassium concentrations for between $30 \mathrm{sec}$ and $30 \mathrm{~min}$ had no effect on $\mathrm{nAChR}$ phosphorylation. This result suggests that 
potassium depolarization does not stimulate ion flux through voltage-sensitive calcium channels that regulates $\mathrm{nAChR}$ phosphorylation.

To investigate directly the role of voltage-sensitive calcium channels in regulating $\mathrm{nAChR}$ phosphorylation, myotubes were treated with the calcium channel agonist Bay K-8644 in an attempt to mimic the effect of carbamylcholine. nAChR phosphorylation was unaffected by Bay K-8644. This result, in conjunction with the observation that potassium depolarization does not affect $\mathrm{nAChR}$ phosphorylation, suggests that voltagesensitive calcium channels do not play a role in regulating $n \mathrm{AChR}$ phosphorylation. This hypothesis is consistent with the observation that voltage-sensitive calcium channels are mainly distributed in transverse tubules and not in the plasma membrane of myotubes (Fosset et al., 1983; Schmid et al., 1984). Therefore, the calcium conducted by these channels may not be in proximity to regulate calcium-dependent protein kinases that phosphorylate the nAChR. However, the observation that antagonists of voltage-sensitive calcium channels partially inhibited carbamylcholine-stimulated $\mathrm{nAChR}$ phosphorylation appears to suggest that both $\mathrm{nAChRs}$ and voltage-sensitive calcium channels participate in regulating $\mathrm{nAChR}$ phosphorylation. Another possibility is that antagonists of voltage-sensitive calcium channels also interact with and inhibit the nAChR ion channel. Indeed, evidence that organic calcium channel antagonists directly inhibit $\mathrm{nAChR}$ channel activity has been reported (Chang et al., 1990). While voltage-sensitive calcium channels cannot be excluded, these findings taken together are in favor of the hypothesis that calcium flux through the nAChR rather than through voltage-sensitive calcium channels stimulates a protein kinase to phosphorylate the $\mathrm{nAChR}$.

Phosphorylation of the $\mathrm{nAChR}$ has been shown to be regulated by the calcium- and phospholipid-dependent PKC. The Torpedo $\mathrm{nAChR} \delta$-subunit is a substrate in vitro for PKC (Safran et al., 1987; Miles and Huganir, 1988). Phorbol ester treatment of chick myotubes increases $\mathrm{nAChR} \delta$-subunit phosphorylation and disrupts nAChR clustering (Ross et al., 1987). The effects of phorbol esters on $\mathrm{nAChR}$ clustering and phosphorylation are mimicked by carbamylcholine (Ross et al., 1988). Here we report that phosphorylation of the rat nAChR $\gamma-, \delta$-, and ' $\delta^{\prime}$-subunits increased in the presence of phorbol esters, suggesting that the $\mathrm{nAChR}$ is also a substrate for PKC at the mammalian neuromuscular junction. Moreover, carbamylcholine increased phosphorylation of the nAChR $\gamma-, \delta$-, and $\delta^{\prime}$-subunits in a manner similar to that induced by phorbol esters. However, chronic treatment of myotubes with phorbol esters, resulting in downregulation of $\mathrm{PKC}$ activity, revealed that $\mathrm{PKC}$ is apparently not an essential component of the biochemical pathway that leads to $\mathrm{nAChR}$ phosphorylation in response to carbamylcholine.

The Torpedo nAChR is not a substrate for calcium/calmodulin-dependent protein kinase II despite the presence of this enzyme in electric organ postsynaptic membrane preparations (Huganir and Greengard, 1983; Zavoico et al., 1984). Treatment of myotubes with W7, a calmodulin inhibitor, did not attenuate carbamylcholine-stimulated $\mathrm{nAChR}$ phosphorylation, indicating that a calcium/calmodulin-dependent protein kinase is not involved in this process (data not shown).

Phosphopeptide mapping revealed that carbamylcholine, phorbol esters, and forskolin treatment increase phosphorylation of the same nAChR $\gamma$ - and $\delta$-subunit phosphopeptides. This finding is consistent with the observation that PKC and cAMP-dependent protein kinase phosphorylated in vitro the

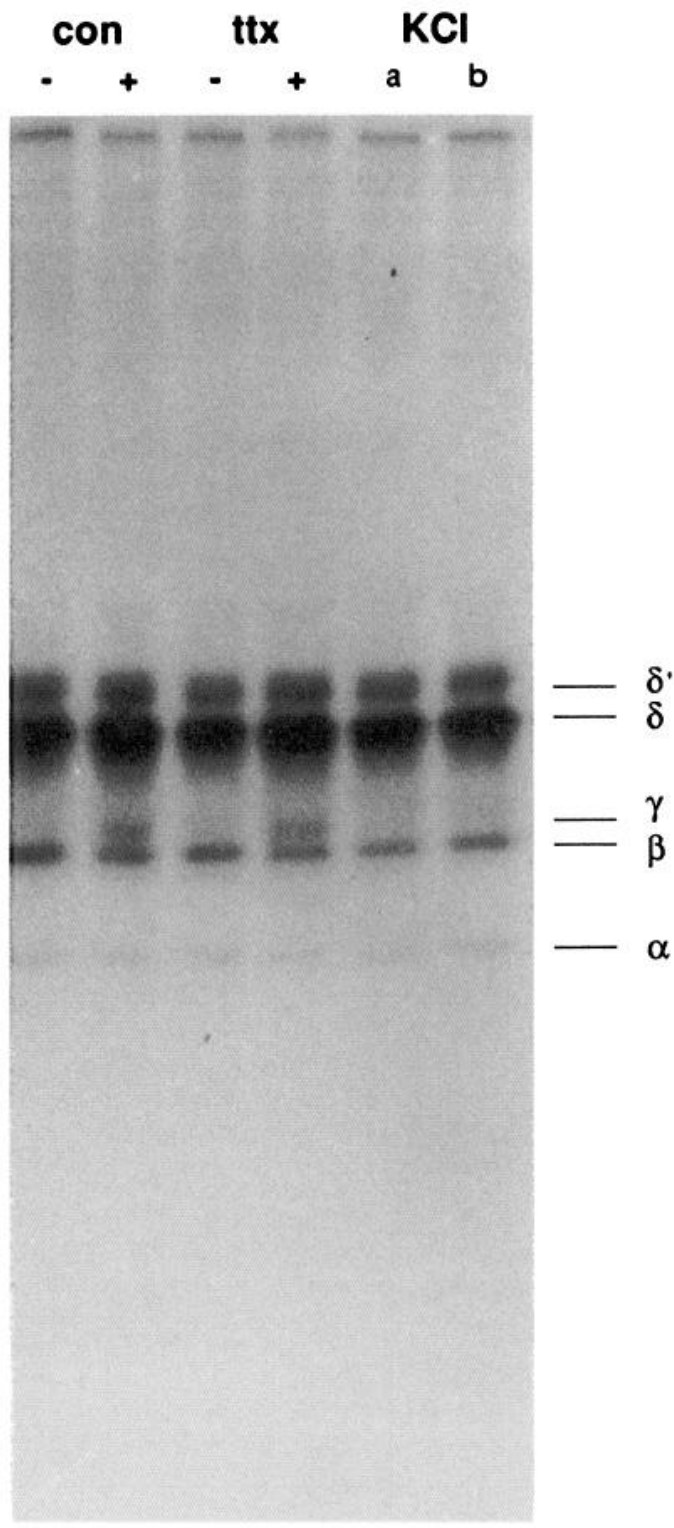

Figure 6. Effect of TTX on carbamylcholine-stimulated ACh receptor phosphorylation and of potassium depolarization on $\mathrm{ACh}$ receptor phosphorylation in myotube cultures. Rat muscle cell primary cultures were metabolically labeled with radioactive phosphate as described for Figure $1 A$. TTX $(t t x)(0.5 \mu \mathrm{M})$ was added to myotube cultures $10 \mathrm{~min}$ prior to the addition of water $(-)$ or carbamylcholine $(500 \mu \mathrm{M})(+)$ for $30 \mathrm{~min}$. Potassium $(\mathrm{KCl})(30 \mathrm{~mm})$ was added for $3(a)$ or $30(\mathrm{~b}) \mathrm{min}$. Myotube cultures were solubilized and ACh receptors were isolated and analyzed as described for Figure $1 \mathrm{~A}$.

same peptide derived from the Torpedo $\mathrm{nAChR} \delta$-subunit (Safran et al., 1987). The rat nAChR $\gamma$-subunit does not, however, contain consensus phosphorylation sites for either of these protein kinases (Miles and Huganir, 1988; Witzemann et al., 1990). Interestingly, the $\epsilon$-subunit, which replaces the $\gamma$-subunit during development of the neuromuscular junction and is likely to be present in myotube cultures (Martinou and Merlie, 1991), does contain consensus sequences for protein kinases that phosphorylate seryl residues (Miles and Huganir, 1988; Witzemann et al., 1990). Therefore, phosphorylation of the $52 \mathrm{kDa}$ subunit may be occurring on a subpopulation of $n A C h R s$ that contain the $\epsilon$ - rather than $\gamma$-subunit. 

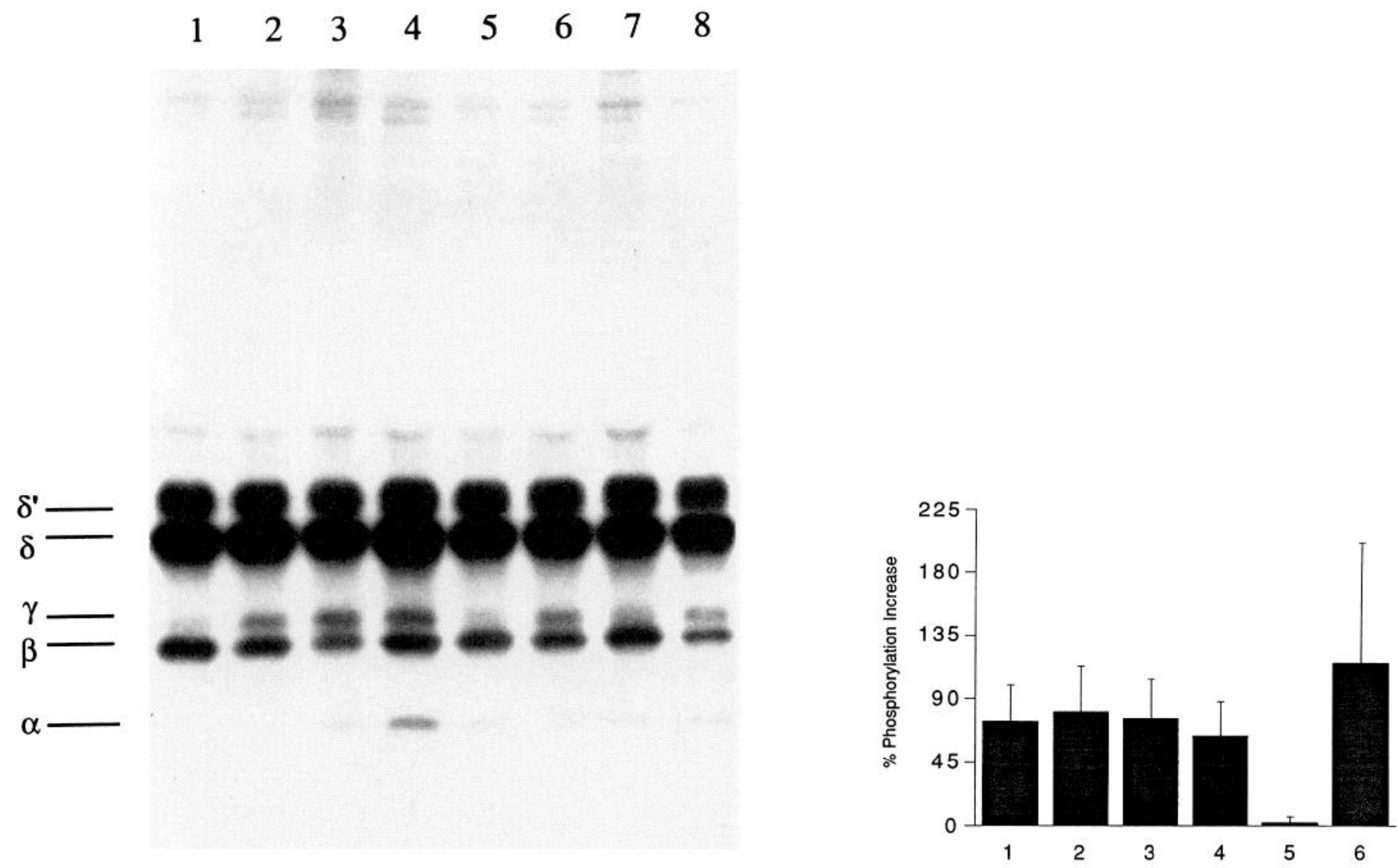

Figure 7. Effect of long-term phorbol ester treatment on carbamylcholine-stimulated ACh receptor phosphorylation in myotubes. A, Rat muscle cell primary cultures were incubated with 4- $\alpha$-PMA (lanes 1-4) or PMA (lanes 5-8) (100 nM) for 12-15 hr. The culture media were removed and the myotubes were metabolically labeled with radioactive phosphate as described for Figure $1 A$. Water (lanes 1 and 5 ), carbamylcholine (500 $\mu \mathrm{M})$ (lanes 2 and 6), PMA (100 nM) (lanes 3 and 7), or forskolin $(20 \mu \mathrm{M})$ and Ro 20-1724 (35 $\mu \mathrm{M})$ (lanes 4 and 8$)$ was added to the cultures for 20 min. Myotube cultures were solubilized and $\mathrm{ACh}$ receptors were isolated and analyzed as described for Figure $1 A$. $B$, Rat muscle cell primary cultures were incubated with 4- $\alpha$-PMA (columns 1-3) or PMA (columns 4-6) (100 nM) for 12-15 hr as described above for $A$. Carbamylcholine (500 $\mu \mathrm{M}$ ) (columns 1 and 4), PMA (100 nM) (columns 2 and 5), or forskolin $(20 \mu \mathrm{M})$ plus Ro 20-1724 (35 $\mu \mathrm{M})($ columns 3 and 6$)$ was added to the cultures for $20 \mathrm{~min}$. Myotube cultures were solubilized and $\mathrm{ACh}$ receptors were isolated and analyzed as described for Figure $1 A$. The ACh receptor $\gamma$-subunit was excised from the gel and the ${ }^{32} \mathrm{P}$-phosphate content was quantitated by liquid scintillation counting. The percentage increase in phosphorylation in each case was calculated with respect to corresponding unstimulated cultures. Error bars represent SEM of three experiments.

Phosphorylation of the $\mathrm{nAChR}$ on serine has been directly and indirectly implicated in accelerating agonist-mediated nAChR desensitization (Huganir et al., 1986; Middleton et al., 1986, 1988; Eusebi et al., 1987; Mulle et al., 1988) and in potentiating synaptic responses at the developing neuromuscular junction (Lu et al., 1993). Phosphorylation of the nAChR may now be seen to be accomplished by distinct mechanisms of receptor regulation that converge to affect $\mathrm{nAChR}$ functional activity similarly. For example, heteroregulation occurs when activation of a receptor by a specific first messenger leads to the accumulation of an intracellular second messenger and the stimulation of a protein kinase that phosphorylates the $\mathrm{nAChR}(\mathrm{Hu}$ ganir and Greengard, 1987, 1990). An example of this type of regulation is the demonstration that calcitonin gene-related peptide increases phosphorylation of the nAChR by a mechanism likely to be mediated by cAMP-dependent protein kinase. In the present study, we have obtained evidence that autoregulation plays a role in $\mathrm{nAChR}$ phosphorylation. We propose that the $\mathrm{nAChR}$ stimulates a calcium-dependent protein kinase activity by virtue of its ability to conduct calcium ions across the plasma membrane. This implies that in addition to depolarization of the postsynaptic cell, the nAChR transduces another signal via the second messenger calcium that directly stimulates a calcium-sensitive protein kinase.

The $\mathrm{nAChR}$ belongs to a family of ligand-gated ion channels that are regulated by protein phosphorylation (Swope et al., 1992). The permeability of certain of these ligand-gated ion channels for the second messenger calcium expands the potential signaling pathways that may result in modulation of synaptic transmission (Fukunaga et al., 1992). For example, in the CNS activation of NMDA receptors and the subsequent entry of calcium is considered to be an essential component for the induction of long-term potentiation (Burden and McKay, 1990). It now appears that activation of nAChRs includes a feedback signal in the form of protein phosphorylation that may regulate functional properties of the $\mathrm{AChR}$, and thus provides another mechanism of synaptic modulation.

\section{References}

Burden SJ, McKay RDG (1990) Quantum mechanics of synapses. Cell 63:7-8.

Bursztajn S, Schneider LW, Jong Y-J, Berman SA (1988) Phorbol esters inhibit the synthesis of acetylcholine receptors in cultured muscle cells. Biol Cell 63:57-65.

Chang CC, Huang CY, Hong SJ (1990) Organic calcium channel an- 
tagonists provoke acetylcholine receptor autodesensitization on train stimulation of motor nerve. Neuroscience 38:731-742.

Changeux J-P, Devillers-Thiéry A, Chemouilli P (1984) Acetylcholine receptor: an allosteric protein. Science 225:1333-1345.

Decker ER, Dani JA (1990) Calcium permeability of the nicotinic acetylcholine receptor: the single-channel calcium influx is significant. J Neurosci 10:3413-3420.

Eusebi FM, Molinaro M, Zani BM (1985) Agents that activate protein kinase $C$ reduce acetylcholine sensitivity in cultured myotubes. J Cell Biol 100:1339-1342.

Fosset M, Jaimovich E, Delpont E, Lazdunski M (1983) $\left[{ }^{3} \mathrm{H}\right]$ nitrendipine receptors in skeletal muscle. J Biol Chem 258:6086-6092.

Froehner SC, Douville K, Klink S, Culp WJ (1983) Monoclonal antibodies to cytoplasmic domains of the acetylcholine receptor. J Biol Chem 258:7112-7120.

Fukunaga K, Soderling TR, Miyamoto E (1992) Activation of $\mathrm{Ca}^{+2 /}$ calmodulin-dependent protein kinase II and protein kinase $\mathrm{C}$ by glutamate in cultured rat hippocampal neurons. J Biol Chem 267:2252722533.

Giovanelli A, Grassi F, Mattei E, Mileo AM, Eusebi F (1991) Acetylcholine induces voltage-independent increase of cytosolic calcium in mouse myotubes. Proc Natl Acad Sci USA 88:10069-10073.

Green WN, Ross AF, Claudio T (1991) Acetylcholine receptor assembly is stimulated by phosphorylation of its $\gamma$ subunit. Neuron 7:659666.

Hopfield JF, Tank DW, Greengard P, Huganir RL (1988) Functional modulation of the nicotinic acetylcholine receptor by tyrosine phosphorylation. Nature 336:677-680.

Huganir RL, Greengard P (1983) cAMP-dependent protein kinase phosphorylates the nicotinic acetylcholine receptor. Proc Natl Acad Sci USA 80:1130-1134.

Huganir RL, Greengard P (1990) Regulation of neurotransmitter receptor desensitization by protein phosphorylation. Neuron 5:555567.

Huganir RL, Miles K, Greengard P (1984) Phosphorylation of the nicotinic acetylcholine receptor by an endogenous tyrosine specific protein kinase. Proc Natl Acad Sci USA 81:6968-6972.

Huganir RL, Delcour AH, Greengard P, Hess GP (1986) Phosphorylation of the nicotinic acetylcholine receptor regulates its rate of desensitization. Nature 321:774-776.

Laemmli UK (1970) Cleavage of structural proteins during the assembly of the head of bacteriophage T4. Nature 227:680-685.

Lu B, Fu W-m, Greengard P, Poo M-m (1993) Calcitonin gene-related peptide potentiates synaptic responses at developing neuromuscular junction. Nature 363:76-79.

Martinou J-C, Merlie JP (1991) Nerve-dependent modulation of acetylcholine receptor $\epsilon$-subunit gene expression. J Neurosci 11:12911299.

Middleton P, Jaramillo F, Schuetze SM (1986) Forskolin increases the rate of acetylcholine receptor desensitization at rat soleus endplates. Proc Natl Acad Sci USA 83:4967-4971.

Middleton P, Rubin LL, Schuetze SM (1988) Desensitization of acetylcholine receptors in rat myotubes is enhanced by agents that elevate intracellular cAMP. J Neurosci 8:3405-3412.

Miles K, Huganir RL (1988) Protein phosphorylation of nicotinic acetylcholine receptors. Mol Neurobiol 2:91-124.

Miles K, Anthony DT, Rubin I.I, Greengard P, Huganir RL (1987) Regulation of nicotinic acetylcholine receptor phosphorylation in rat myotubes by forskolin and cAMP. Proc Natl Acad Sci USA 84:65916595.

Miles K, Greengard P, Huganir RL (1989) Calcitonin gene-related peptide regulates phosphorylation of the nicotinic acetylcholine receptor in rat myotubes. Neuron 2:1517-1524.
Mishina M, Takai T, Imoto K, Noda M, Takahashi T, Numa S, Methfessel C, Sakmann B (1986) Molecular distinction between fetal and adult forms of muscle acetylcholine receptor. Nature 321:406-411.

Mulle C, Benoit P, Pinset C, Roa M, Changeux J-P (1988) Calcitonin gene-related peptide enhances the rate of desensitization of the nicotinic acetylcholine receptor in cultured muscle cells. Proc Natl Acad Sci USA 85:5728-5732.

Qu ZE, Moritz E, Huganir RL (1990) Regulation of tyrosine phosphorylation of the nicotinic acetylcholine receptor at the rat neuromuscular junction. Neuron 2:367-378.

Reynolds J, Karlin A (1978) Molecular weight in detergent solution of acetylcholine receptor from Torpedo californica. Biochemistry 17: 2023-2038.

Ross AF, Rapuano M, Schmidt JH, Prives JM (1987) Phosphorylation and assembly of nicotinic acetylcholine receptor subunits in cultured chick muscle cells. J Biol Chem 262:14640-14647.

Ross A, Rapuano M, Prives J (1988) Induction of phosphorylation and cell surface redistribution of acetylcholine receptors by phorbol ester and carbamylcholine in cultured chick muscle cells. J Cell Biol 107:1139-1145.

Safran A, Eisenberg RS, Neumann D, Fuchs S (1987) Phosphorylation of the acetylcholine receptor by protein kinase $\mathrm{C}$ and identification of the phosphorylation site within the receptor $\delta$ subunit. J Biol Chem 262:10506-10510.

Schmid A, Renaud JF, Fosset M, Meaux JP, Lazdunski M (1984) The nitrendipine-sensitive $\mathrm{Ca}^{+2}$ channel in chick muscle cells and its appearance during myogenesis in vitro and in vivo. J Biol Chem 259: $11366-11372$.

Smith MM, Merlie JP, Lawrence JC Jr (1987) Regulation of phosphorylation of nicotinic acetylcholine receptors in mouse $\mathrm{BC} 3 \mathrm{H} 1$ myocytes. Proc Natl Acad Sci USA 84:6601-6605.

Smith MM, Merlie JP, Lawrence JC Jr (1989) $\mathrm{Ca}^{+2}$-dependent and cAMP-dependent control of nicotinic acetylcholine receptor phosphorylation in muscle cells. J Biol Chem 264:12813-12819.

Solanski V, Slaga TJ, Callahan M, Hubermann E (1981) Down regulation of specific binding of $20{ }^{3} \mathrm{H}$-phorbol-12,13-dibutyrate and phorbol ester induced differentiation of human promyelocytic leukemia cells. Proc Natl Acad Sci USA 78:1/22-1/25.

Strübing C, Hering S, Glossman H (1993) Evidence for an external location of the dihydropyridine agonist receptor site on smooth muscle and skeletal muscle calcium channels. Br J Pharmacol 108:884891.

Swope SL, Moss SJ, Blackstone C, Huganir RI, (1992) Phosphorylation of ligand-gated ion channels: a possible mode of synaptic plasticity. FASEB J 6:2514-2523.

Wagner K, Edson K, Heginbotham L, Post M, Huganir RL, Czernik AJ (1991) Determination of the tyrosine phosphorylation sites of the nicotinic acetylcholine receptor. J Biol Chem 266:23784-23789.

Wallace BG, Qu Z, Huganir RL (1991) Agrin induces phosphorylation of acetylcholine receptors. Neuron 6:869-878.

Witzemann V, Stein E, Barg B, Konno T, Koenen M, Kues W, Criado M, Hofman M, Sakmann B (1990) Primary structure and functional expression of the $\alpha, \beta, \gamma, \delta$ and $\epsilon$ subunits of the acetylcholine receptor from rat muscle. Eur J Biochem 194:437-448.

Yee GH, Huganir RL (1987) Determination of the sites of cAMPdependent phosphorylation on the nicotinic acetylcholine receptor. J Biol Chem 262:16748-16753.

Zavoico GB, Comerci C, Subers E, Eagen JJ, Huang C-K, Feinstein M, Smilowitz H (1984) cAMP, not $\mathrm{Ca}^{+2} /$ calmodulin, regulates the phosphorylation of acetylcholine receptor in Torpedo californica electroplax. Biochim Biophys Acta 770:225-229. 